\title{
Special issue: analysis and modelling of sediment transfer in Mediterranean river basins
}

\author{
José Carlos de Araújo • Ramon J. Batalla • Axel Bronstert
}

Received: 7 October 2014 / Accepted: 7 October 2014 / Published online: 1 November 2014

(C) Springer-Verlag Berlin Heidelberg 2014

The characteristic conditions found in most Mediterranean and many other semiarid regions are those situations where current water use already equals and often exceeds water availability and where the hydro-meteorological regime shows a strong variability. In addition, water demand is commonly out-of-phase in relation to water resources, especially at the seasonal scale. If those areas rely on surface water resources to a large extent, they are particularly vulnerable to severe erosion (because of scarce vegetation cover of the soil and high rainfall intensity/energy), loss of fertile soils and subsequent sedimentation of reservoirs that are designed for water supply. As a consequence, this loss of reservoir retention volume may lead to a significant reduction of water availability within a period of a few years or decades. Therefore, erosion and sedimentation issues have to be taken into account when analysing and implementing long-term sustainable strategies to secure future water supply through water management and to sustain soil productivity through land-use management in upstream catchments.

In this context, it is necessary to focus research and innovative management issues on "typical" scales in time and space. From a scientific perspective, the adequate spatial process scales range from the plot to field or river-reach scale. The model scale also ranges from plot scale but expands to the

J. C. de Araújo ( $\square)$

Department of Agricultural Engineering, Federal University of Ceará, Fortaleza, CE 60356-000, Brazil

e-mail: jcaraujo@ufc.br

\section{R. J. Batalla}

Fluvial Dynamics Research Group - RIUS, University of Lleida, 25198 Lleida, Catalonia, Spain

A. Bronstert

Institute of Earth and Environmental Science, University of Potsdam, Karl-Liebknecht-Str. 24-25, Golm, 14476 Potsdam, Germany meso-scale of river basins up to several thousands of square kilometres. From a management perspective, the spatial scale of interest is the meso-scale (or intermediate to large catchments scale) because this is the scale most relevant for management of water and land resources. Furthermore, it is important to account for the relevant landscape components (and their driving processes), such as hillslopes (runoff and erosion processes on the soil surface), channel network (transfer from sources i.e. connectivity and sediment transport in river systems) and lakes or reservoirs (deposition of sediments).

The scientifically sound assessment of generation, transfer and storage processes of water and sediment fluxes can be conducted in a dynamic and quantitative way by field monitoring, on the one hand, and the application and adaptation of adequate hydrological and sediment-transport models, on the other. Due to upstream-downstream relationships, connectivity factors that influence runoff generation, sediment production and water resources, as well as the effects of water management measures, usually affect the entire area of river basins and thus need to be included in this assessment.

This special issue of the Journal of Soils and Sediments deals with the research questions identified above. It comprises 11 articles with different methodological backgrounds (monitoring/measurement techniques, methods of data analysis and process-oriented modelling); from different Mediterranean regions, in particular from the Iberian Peninsula, Europe, and from northeast Brazil; different spatial scales (from micro-catchments covering a few hectares up to the large catchments of the Lower Ebro and the Upper Jaguaribe, i.e. the scale of $10^{5} \mathrm{~km}^{2}$ ); and different time scales (from the event scale, i.e. a few hours, up to several decades).

Most of the articles are based on selected presentations given at the 6th International Conference on Water Resources and Environment Research that was convened at Koblenz (Germany) from 3 to 7 June 2013. The focus of the conference was to foster an integrative understanding of water and the 
environment. It brought together physical, biological, chemical, statistical, socioeconomic and technical expertise in order to discuss solutions for transient environmental boundary conditions.

The presentations that form the basis of the articles for this special issue were given in the conference session on "Analysis and modelling of sediment transfer in Mediterranean landscapes: Hillslope processes, river system connectivity and reservoir yields". The session focused on the linkages amongst basin and river dynamics and human impacts as a basis for environmental management, particularly for Mediterranean river basins, of relevance to dry land regions. Sediment sources, erosion processes and transfer to fluvial systems, fluvial dynamics and sediment transport, together with aspects of water and sediment management, were all considered from both a monitoring and modelling perspective. We believe that this multi-method approach is one of the fundamental bases for the present-day diagnosis of, and future strategies for, environmental management of rivers in areas especially prone to change, such as the Mediterranean regions. The papers reflect a variety of hydrological and geomorphological processes at the basin and river levels, as well as their interactions and their relationships with the human activities that can interfere with them. A wide range of methodologies are presented to assess the various problems addressed, including modelling approaches, together with sediment erosion and transport monitoring, and storage and transfer techniques. Connectivity, erosion, sediment transport, modelling and reservoirs are the most frequently cited keywords that readers will find throughout the volume. Some of the main findings of the papers are summarized as follows.

Francke et al. (2014) assessed water and sediment yields from subbasins of the Isábena River. The work shows the usefulness of an innovative data analysis method (e.g. nonparametric and Bayesian regression) to reconstruct sediment concentrations and further reconstruct the hydrosedimentological regime of the catchment using discharge and rainfall data plus different aggregation levels of these as ancillary predictors. The Monte Carlo simulations allowed the specification of monthly sediment yields and their uncertainty. The Isábena catchment shows high erosion dynamics with great variability in space and time, owing to its particular lithology, vegetation and sediment production patterns.

Bussi et al. (2014) emphasized the need for a quantitative assessment of climate change impacts as a basis for a sound environmental policy in Mediterranean areas. The authors implement a sediment model by taking advantage of proxy sediment information provided by reservoir bottom deposits, with the model also being compared with gauged suspended sediment data of the Ésera River (south central Pyrenees). The model is then coupled with future precipitation and temperature scenarios obtained from climate models, providing a measure of the impact of climate change on soil erosion and sediment yields.

Medeiros et al. (2014) studied key processes controlling sediment connectivity in the semiarid Upper Jaguaribe Basin (northeast Brazil) at different spatial scales. Water and sediment fluxes were assessed from observed discharge, sediment concentrations and reservoir siltation data, and the WASA-SED model was used to quantify water and sediment transfer in a systematic manner. The results show that sediment propagation is constrained by low surface runoff rates, which is the main feature breaking sediment connectivity and limiting sediment transfer from the hillslopes to the drainage system. Reservoirs are also important barriers, showing increasing sediment retention with basin scale.

Brosinsky et al. (2014a) point out that potential sediment sources and their contributions can be discriminated based on their distinctive characteristics (fingerprints). Visible near-infrared and shortwave infrared reflectance of soil is an alternative to traditional fingerprinting (e.g. geochemistry and magnetism). Sampling was undertaken in the Isábena River basin where three source types (i.e. badlands, forest/grassland and an aggregation of other sources) could be identified based on spectral parameters. Results suggest that combinations of spectral properties can be used for mixing model analyses of a restricted number of sources.

Further, Brosinsky et al. (2014b) show how spectroscopy allows inexpensive analyses even of intra-event sediment variability. In the Isábena River, they studied changes in source contributions of fluvial sediment based on its spectral properties and used a mixing model to determine source contributions. Inchannel sediments are mainly influenced by grain size and seasonal variability, while the role of tributaries is of minor importance. Sediment sources varied between and within flood events, with the badlands always being the major source. A combination of spectral and conventional fingerprint properties could permit further discrimination of more source types.

Foerster et al. (2014) emphasized the central role that connectivity plays in the redistribution of water and sediments in dry land areas characterized by high erosion rates. Their work assesses sediment connectivity in two adjacent catchments of the Isábena River using a quantitative index based on fractional vegetation cover and topography data, using a multiple endmember spectral mixture analysis approach. Areas behave differently with regard to the spatial distribution of vegetation abundances and topographic barriers. Connectivity allows hot spot areas of erosion to be identified and the effects of control measures scenarios to be studied.

Bronstert et al. (2014) present an integrated, processoriented modelling system for the quantitative assessment of water and sediment fluxes in catchments at the meso-scale. The model is tailored for dry land characteristics coupled with 
hillslope erosion, sediment transport and reservoir deposition. The non-linear and flashy runoff generation and sediment dynamics are dealt with by accounting for connectivity at intersections of landscape compartments. Data for model development and application are obtained for catchments in Spain and Brazil. Connectivity plays a key role, regarding both the total mass of water and sediment transported and also the transport time through the catchments.

López-Tarazón and Batalla (2014) analyse dominant discharges and their relation to effective and bankfull discharges. Dominant discharges have a central role in geomorphology, both for the interpretation of the river form and process relations and for the estimation of sediment loads. Effective discharge for sediment transport is not solely associated with bankfull but to a wider range of discharges. Results suggest that dominant discharge may play a lesser role in terms of sediment load in non-supply-limited fluvial systems and/or in rivers that permanently work close to full transport capacity.

Piqué et al. (2014) examine the role of in-channel sediment storage, a fundamental component of a river's sediment budget not frequently analysed. Work was undertaken in the Isábena River and data were obtained using a resuspension cylinder deployed seasonally at representative river sections. Results show an annual sedimentary cycle that works uninterruptedly due to the high connectivity between production areas and river network, with the sediment being produced in badlands during winter, transferred to the main channel during spring, stored in the river during summer and, finally, exported out of the basin by the autumn floods.

Díaz et al. (2014) study the effectiveness of retaining sediments from check dams constructed in the badlands of the Corneja River (central Spain), using a new topographical method. The topography of sediment deposits is compared with those of simplified geometric figures. Results show a significant discrepancy between the two approaches, with differences shown to be more significant in larger check dams. New approaches appear to be more likely to estimate erosion rates and sediment yield correctly, thus leading to a better understanding of the effects of check dams on badlands restoration.

Finally, Tena et al. (2014) analyse the spatial and temporal dynamics of suspended sediment transport during flushing flows in a large regulated river, the lower Ebro River (NE Spain). Relationships between sediment and discharge were examined during six artificial releases. Flow and sediment dynamics were mostly influenced by the discharge routing velocity and sediment waves: in addition, similar magnitude floods generated higher sediment peaks in autumn than in spring. The results point to the importance of understanding sediment transport in a large regulated river such as the Ebro to achieve the sustainability of the riverine and deltaic ecosystems.

This volume presents innovative methods and case studies to analyse, quantify and model runoff and sediment transfer processes from the plot scale to the upper meso-scale in Mediterranean and other dry land regions. The main landscape components, i.e. hillslopes, river system and lakes/reservoirs, are addressed, including a special focus on the hydro-sedimentological connectivity within and between those components. The research results enhance our process knowledge, methods of data analysis and modelling capability of water and sediment fluxes in semiarid environments. Results partly address the spatial scales relevant for water and land management, therefore also informing the sustainable use and management of water and soil resources.

We are deeply indebted to the reviewers who undertook thorough revisions of the papers submitted for publication in this special issue. We further want to thank Moira Ledger from the editorial office of JSS for her continuing and very professional support which made it possible to put this special issue together.

Acknowledgments The authors acknowledge the support from the Economy and Knowledge Department of the Catalan Government through the Consolidated Research Group 2014 SGR 645 (RIUS-Fluvial Dynamics Research Group) for the following contributions to this special issue: Bronstert et al. (2014), Brosinsky et al. (2014b), Bussi et al. (2014), Francke et al. (2014), López-Tarazón and Batalla (2014), Piqué et al. (2014) and Tena et al. (2014).

\section{References}

Bronstert A, de Araújo JC, Batalla RJ, Cunha Costa A, Delgado JM, Francke T, Foerster S, Guentner A, López-Tarazón JA, Mamede GL, Medeiros PH, Mueller E, Vericat D (2014) Process-based modeling of erosion, sediment transport and reservoir siltation in meso-scale semi-arid catchments. J Soils Sediments. doi:10.1007/ s11368-014-0994-1

Brosinsky A, Foerster S, Segl K, Kaufmann C (2014a) Spectral fingerprinting: sediment source discrimination and contribution modelling of artificial mixtures based on VNIR-SWIR spectral properties. J Soils Sediments. doi:10.1007/s11368-014-0925-1

Brosinsky A, Foerster S, Segl K, López-Tarazón JA, Piqué G, Bronstert A (2014b) Spectral fingerprinting: characterizing suspended sediment sources by the use of VNIR-SWIR spectral information. $J$ Soils Sediments. doi:10.1007/s11368-014-0927-z

Bussi G, Francés F, Horel E, López-Tarazón JA, Batalla RJ (2014) Modelling the impact of climate change on sediment yield in a highly erodible Mediterranean catchment. J Soils Sediments. doi: 10.1007/s11368-014-0956-7

Díaz V, Mongil J, Navarro J (2014) Topographical surveying for improved assessment of sediment retention in check dams applied to a Mediterranean badlands restoration site (Central Spain). J Soils Sediments. doi:10.1007/s11368-014-0958-5 
Foerster S, Wilczok C, Brosinsky A, Segl K (2014) Assessment of sediment connectivity from vegetation cover and topography using remotely sensed data in a dryland catchment in the Spanish Pyrenees. J Soils Sediments. doi:10.1007/s11368-014-0992-3

Francke T, Werb S, Sommerer E, López-Tarazón JA (2014) Analysis of runoff, sediment dynamics and sediment yield of subcatchments in the highly erodible Isábena catchment, Central Pyrenees. J Soils Sediments. doi:10.1007/s11368-014-0990-5

López-Tarazón JA, Batalla RJ (2014) Dominant discharges for suspended sediment transport in a highly active Pyrenean river. J Soils Sediments. doi:10.1007/s11368-014-0961-x
Medeiros PHA, de Araújo JC, Mamede GL, Creutzfeldt B, Güntner A, Bronstert A (2014) Connectivity of sediment transport is a semiarid environment: a synthesis for the Upper Jaguaribe Basin, Brazil. J Soils Sediments. doi:10.1007/s11368-014-0988-Z

Piqué G, López-Tarazón JA, Batalla RJ (2014) Variability of in-channel sediment storage in a river draining highly erodible areas (the Isábena, Ebro basin). J Soils Sediments. doi:10.1007/s11368-0140957-6

Tena A, Vericat D, Batalla RJ (2014) Suspended sediment dynamics during flushing flows in a large impounded river (the lower River Ebro). J Soils Sediments. doi:10.1007/s11368-014-0987-0 